\title{
SynGAP Regulates Steady-State and Activity-Dependent Phosphorylation of Cofilin
}

\author{
Holly J. Carlisle, Pasquale Manzerra, Edoardo Marcora, and Mary B. Kennedy \\ Division of Biology, California Institute of Technology, Pasadena, California 91125
}

SynGAP, a prominent Ras/Rap GTPase-activating protein in the postsynaptic density, regulates the timing of spine formation and trafficking of glutamate receptors in cultured neurons. However, the molecular mechanisms by which it does this are unknown. Here, we show that synGAP is a key regulator of spine morphology in adult mice. Heterozygous deletion of synGAP was sufficient to cause an excess of mushroom spines in adult brains, indicating that synGAP is involved in steady-state regulation of actin in mature spines. Both Ras-and Rac-GTP levels were elevated in forebrains from adult synGAP${ }^{+/-}$mice. Rac is a well known regulator of actin polymerization and spine

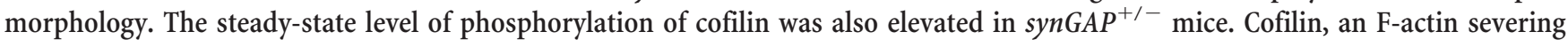
protein that is inactivated by phosphorylation, is a downstream target of a pathway regulated by Rac. We show that transient regulation of cofilin by treatment with NMDA is also disrupted in synGAP mutant neurons. Treatment of wild-type neurons with $25 \mu \mathrm{M}$ NMDA triggered transient dephosphorylation and activation of cofilin within $15 \mathrm{~s}$. In contrast, neurons cultured from mice with a homozygous or heterozygous deletion of synGAP lacked the transient regulation by the NMDA receptor. Depression of EPSPs induced by a similar treatment of hippocampal slices with NMDA was disrupted in slices from synGAP${ }^{+/-}$mice. Our data show that synGAP mediates a rate-limiting step in steady-state regulation of spine morphology and in transient NMDA-receptor-dependent regulation of the spine cytoskeleton.

Key words: cytoskeleton; actin; spines; LTD; Ras; Rac

\section{Introduction}

Excitatory neurons in the CNS form synaptic connections onto dendritic protrusions called spines. The shapes and sizes of spines are remarkably plastic (Fischer et al., 1998; Lüscher et al., 2000). They can emerge, recede, and change their morphology in seconds by remodeling the underlying actin cytoskeleton (Halpain, 2000; Matus, 2000). The morphology of spines is related to synaptic strength; for example, the number of AMPA receptors in the postsynaptic membrane correlates with spine size (Harris and Stevens, 1989; Nusser et al., 1998). Changes in spine morphology are thus an important aspect of synaptic plasticity (Okamoto et al., 2004; Kramár et al., 2006; Chen et al., 2007).

A complex of proteins known as the postsynaptic density (PSD) resides below the postsynaptic surface of a spine (Kennedy, 1997, 2000; Kim and Sheng, 2004). It contains transmembrane receptors, scaffold proteins, and signaling molecules with numerous attachments to actin filaments. NMDA-type glu-

\footnotetext{
Received Sept. 30, 2008; accepted 0ct. 27, 2008.

This work was supported by National Institutes of Health (NIH) Grant NS17660 to M.B.K., by NIH Dorothy Kirschstein Fellowship F32NS47894 to H.J.C., and by donations to Caltech from Parna L. Joyce, Nancy A. E. Hicks, and the Gordon and Betty Moore Foundation. We thank Dr. Joshua Sanes (Harvard, Cambridge, MA) for GFP line-M transgenic mice, Dr. Brent Lindquist (Stony Brook University, Stony Brook, NY) for 3DMA spine analysis software, and Alan Rosenstein and Leslie Schenker for technical assistance.

Correspondence should be addressed to Dr. Mary B. Kennedy, Department of Biology, California Institute of Technology, 1200 East California Boulevard, MC 216-76, Pasadena, CA 91125. E-mail: kennedym@its.caltech.edu.

P. Manzerra's present address: Division of Basic Biomedical Sciences, Sanford School of Medicine of The University of South Dakota, Vermillion, SD 57069.

DOI:10.1523/JNEUROSCI.4695-08.2008

Copyright $\odot 2008$ Society for Neuroscience 0270-6474/08/2813673-11\$15.00/0
}

tamate receptors (NMDA receptors) are at the core of one signaling complex in the PSD that includes rasGRF1 and synGAP (Kennedy et al., 2005). Activation of Ras by NMDA receptors in hippocampal neurons is mediated by RasGRF (Krapivinsky et al., 2003; Li et al., 2006). SynGAP, however, inactivates Ras by stimulating Ras-GTP hydrolysis (Chen et al., 1998; Kim et al., 1998). Thus, the relative activities of RasGRF and synGAP shape the timing and magnitude of NMDA receptor-mediated Ras signaling.

In the present study, we show that $50 \%$ reduction of the level of synGAP is sufficient to cause a significant increase in large, "mushroom" spines on hippocampal pyramidal neurons in brains of adults heterozygous for a synGAP deletion, consistent with our previous studies in cultured synGAP $P^{+/-}$neurons (Vazquez et al., 2004). Because spine morphology is determined by the underlying actin cytoskeleton (Markham and Fifkova, 1986), our observations indicate that synGAP is involved in regulation of actin in spines. Indeed, we found that steady-state levels of activity at several points in the actin regulating pathway that controls phosphorylation/inactivation of the actin-severing protein cofilin (Carlisle and Kennedy, 2005) were elevated in forebrains from adult syn $G A P^{+/-}$mice. Levels of Ras- and RacGTP and activated PAK were elevated; as was the level of phospho-cofilin, its inactive form. Transient dephosphorylation and activation of cofilin in response to NMDAR activation was also abolished in the absence of synGAP. We found that this dephosphorylation is independent of Rac and the PAK1-3 kinase cascade. These findings demonstrate that synGAP contributes to 
control of spine morphology by regulating both steady-state phosphorylation and transient NMDA receptor-dependent dephosphorylation of cofilin. Because synGAP contributes to regulation of the actin cytoskeleton and AMPA receptor insertion through Ras-related pathways (Rumbaugh et al., 2006), our results suggest that synGAP is a critical common network element through which two of the fundamental molecular changes underlying synaptic plasticity are controlled.

\section{Materials and Methods}

Mouse strains. Generation of the synGAP knock-out line is described by Vazquez et al. (2004). The mutant line is maintained in a 129 and C57BL6 mixed background because the mutant line breeds poorly when it is fully out-crossed to C57BL6. Homozygous green fluorescent protein (GFP) line-M transgenic mice (Feng et al., 2000) in a C57BL6 background (a kind gift from Dr. Joshua Sanes, Harvard University, Cambridge, MA) were crossed with synGAP ${ }^{+/-}$mice to visualize dendritic spines in area CA1 of the hippocampus.

Analysis of spines. Three $G F P^{+/-} /$syn $G A P^{+/+}$and $G F P^{+/-} /$syn$G A P^{+/-}$littermate pairs, 3-6 months in age, were perfused transcardially with fixative ( $4 \%$ formaldehyde, $15 \%$ saturated picric acid in $0.1 \mathrm{M}$ PBS) for $20 \mathrm{~min}$. Forebrains ( 3 wild-type and $3 \operatorname{syn} G A P^{+/-}$) were dissected, postfixed overnight at $4^{\circ} \mathrm{C}$, and then $50 \mu \mathrm{m}$ coronal sections were cut with a vibratome and mounted with Prolong Gold antifade reagent. Images were acquired with a Zeiss 510 Meta confocal microscope with a $100 \times 1.4 \mathrm{NA}$ lens and $2 \times$ optical zoom. Images of dendrites (from 10 sections per animal) were reconstructed from stacks of forty $0.2 \mu \mathrm{m}$ optical sections that were preprocessed with blind iterative deconvolution software (Autodeblur) from Autoquant. Spine morphology was analyzed using 3DMA spine analysis software developed in the laboratory of Brent Lindquist (Stony Brook University, Stony Brook, NY) (Koh et al., 2002). By using a geometric approach, the 3DMA software automatically detects and quantifies the three-dimensional structure of dendritic spines from stacks of high-resolution confocal microscopic images (supplemental Fig. 1, available at www.jneurosci.org as supplemental material). The software then assigns the detected spines to one of three morphological categories (thin, stubby, or mushroom) based on the ratio of neck length to head volume (Koh et al., 2002). The investigator was blind to genotype during image acquisition and analysis of spine morphology.

Ras- and Rac-GTP assays. Individual 2- to 6-month-old syn $G A P^{+/-}$or $\operatorname{syn} G A P^{+/+}$littermate forebrains were homogenized with a Teflon-glass homogenizer at $1000 \mathrm{RPM}$ in $4 \mathrm{ml}$ of lysis buffer (50 mM Tris pH 7.5, 10 $\mathrm{mm} \mathrm{MgCl}_{2}, 0.3 \mathrm{M} \mathrm{NaCl}, 2 \%$ IGEPAL, Roche Protease Inhibitor Complete EDTA-free) and nuclei were pelleted at 14,000 $\times g$ for $1 \mathrm{~min}$. One $\mathrm{ml}$ of the supernatant (homogenate) was incubated with agarose beads containing conjugated PAK-binding domain for Rac-GTP (Upstate), and $100 \mu \mathrm{l}$ of homogenate was incubated with beads conjugated with the Raf-1-binding domain for Ras-GTP (Upstate) for $1 \mathrm{~h}$. A similar protocol was followed for pulldown of Ras- and Rac-GTP from cultured hippocampal and cortical neurons. Approximately $250 \mu \mathrm{g}$ of total protein from homogenized cultures were incubated with the beads for Rac-GTP pulldown assays, and $\sim 100 \mu \mathrm{g}$ of protein were used in Ras-GTP assays. The beads were then sedimented and washed 3 times in lysis buffer. Proteins bound to the beads were solubilized in SDS-gel sample buffer and fractionated by SDS-PAGE. Proteins were transferred electrophoretically to nitrocellulose and the filters were incubated with antipan-Ras or anti-Rac1 antibodies (Upstate; 1:1000 dilution). In all cases, $5 \%$ of the initial homogenate input for the pull-down assay was electrophoresed and probed with anti-Ras or Rac antibody and activated levels were normalized to the total input levels of Ras or Rac. Bands were visualized and quantified as described below under immunoblot analysis.

Cell culture and treatment. Hippocampi dissected from mice at embryonic day 16 (E16) or E17 were triturated and plated into wells of 24-well plates coated with $50 \mathrm{ng} / \mathrm{ml}$ poly-D-lysine (Sigma) and $2 \mathrm{ng} / \mathrm{ml} \mathrm{laminin}$ (BD Biosciences) at a density of $\sim 50,000$ neurons/well in Neurobasal medium (Invitrogen) supplemented with B-27 (Invitrogen), $0.5 \mu \mathrm{M}$ Glutamax I (Invitrogen), $25 \mu \mathrm{M}$ glutamate, and $25 \mu \mathrm{M} \beta$-mercaptoethanol
(Sigma). After $3 \mathrm{~d}$ in vitro (3 DIV), cultures were maintained in neurobasal medium (Invitrogen) supplemented with B27, and glutamax-I (Invitrogen) as described previously (Brewer et al., 1993). At 16-18 DIV, cultures were pretreated for $2-4 \mathrm{~h}$ with $1 \mu \mathrm{M}$ TTX and $100 \mu \mathrm{M}$ APV which was removed immediately before NMDA application. The cultures were gently washed twice in HEPES-control salt solution (HCSS; Invitrogen) containing (in mM): $120 \mathrm{NaCl}, 5.4 \mathrm{KCl}, 0.8 \mathrm{MgCl}_{2}, 1.8 \mathrm{CaCl}_{2}, 10 \mathrm{NaOH}$, 20 HEPES, and 5.5 glucose, $\mathrm{pH} 7.4$, and then exposed to $25 \mu \mathrm{M}$ NMDA (Tocris) dissolved in HCSS or to an equal amount of additional HCSS for the durations indicated. After treatment, cells were washed quickly with PBS and extracted with lysis buffer [3\% SDS, 20 mM Tris-Cl, pH 7.5, 10 mм EGTA, $40 \mathrm{~mm} \beta$-glycerophosphate, $2.5 \mathrm{~mm} \mathrm{MgCl}_{2}$, and Protease Inhibitor Complete (Roche) ]. Extracts were heated at $90^{\circ} \mathrm{C}$ for $5 \mathrm{~min}$ and protein concentrations were determined by the bicinchoninic acid method (Pierce) using bovine serum albumin as standard.

SDS-PAGE and immunoblot analysis. Equal amounts of protein from each sample $(15-25 \mu \mathrm{g})$ were dissolved in SDS-PAGE sample buffer, heated at $90^{\circ} \mathrm{C}$ for $5 \mathrm{~min}$, fractionated by SDS-PAGE on $12.5 \%$ acrylamide gels, and transferred to nitrocellulose membranes (Schleicher \& Schuell) in transfer buffer containing $25 \mathrm{~mm}$ Tris, $200 \mathrm{~mm}$ glycine, and $20 \%$ methanol. Membranes were blocked with $5 \%$ milk in TBS buffer $(20$ mм Tris, $150 \mathrm{~mm} \mathrm{NaCl}$ ) and then incubated in primary antibody solution: anti-phospho-cofilin (Cell Signaling), anti-cofilin (Transduction Labs), anti-phospho-Serine 1123 synGAP or anti-synGAP [developed in our laboratory (Oh et al., 2004)], anti-phospho-threonine 286 CaMKII or anti-CaMKII [developed in our laboratory; Affinity Bioreagents (Patton et al., 1993)], anti-phospho-Thr ${ }^{423}$ PAK (Cell Signaling), anti-actin (Sigma). Bound antibodies were detected with IRdye700- or IRdye800conjugated secondary antibody (Rockland) and visualized with the Odyssey Infrared Imaging System (Li-Cor Biosciences). Reported values for phosphorylated proteins were normalized to staining for the total level of the protein or to anti-actin staining, as stated.

Slice preparation and extracellular recording. Hippocampi were dissected from 6- to 12-week-old syn $G A P^{+/-}$and wild-type littermates that were deeply anesthetized with $\mathrm{CO}_{2}$ and killed by cervical dislocation. Hippocampal slices (400 $\mu \mathrm{m}$ thick) were then prepared using standard techniques at room temperature and maintained at $30^{\circ} \mathrm{C}$ in an interfaceslice type recording chamber (Fine Science Tools) in oxygenated (95\% $\mathrm{O}_{2} / 5 \% \mathrm{CO}_{2}$ ) artificial CSF (ACSF) containing $124 \mathrm{~mm} \mathrm{NaCl}, 4.4 \mathrm{~mm} \mathrm{KCl}$, $25 \mathrm{~mm} \mathrm{NaHCO}_{3}, 1 \mathrm{~mm} \mathrm{NaH} \mathrm{PO}_{4}, 2 \mathrm{~mm} \mathrm{CaCl}_{2}, 1.2 \mathrm{~mm} \mathrm{MgSO}_{4}$, and 10 mu glucose. Slices recovered for at least $2 \mathrm{~h}$ before experiments were performed. After recovery, slices were perfused with a modified ACSF containing $4.0 \mathrm{~mm} \mathrm{CaCl}_{2}$ (high- $\mathrm{Ca}^{2+}$ ACSF) to facilitate the induction of long-term depression (LTD) in adult slices (Norris et al., 1996; Delgado et al., 2007). Schaffer collateral/commissural fibers were stimulated with a bipolar, nichrome wire electrode placed in stratum radiatum of the hippocampal CA1 region. Evoked field EPSPs (fEPSPs) in CA1 stratum radiatum were recorded using an extracellular glass microelectrode (5-10 $\mathrm{M} \Omega$ resistance) filled with ACSF. The intensity of presynaptic fiber stimulation was adjusted to evoke fEPSPs with amplitude $\sim 50 \%$ of the maximal fEPSP amplitude that could be elicited in each slice. fEPSPs were then elicited every $30 \mathrm{~s}$ throughout the experiment. After acquiring a stable baseline recording, slices were perfused $25 \mu \mathrm{M}$ NMDA (Calbiochem; dissolved in high-Ca ${ }^{2+}$ ACSF) for $5 \mathrm{~min}$, and then washed in high$\mathrm{Ca}^{2+}$ ACSF for the remainder of the experiment. In a separate set of experiments, slices were prepared as described above and then collected for Western blot analysis 2 min before NMDA treatment (untreated control), or at $0,5,10$, or 15 min after treatment with NMDA ( $25 \mu \mathrm{M}$ for $5 \mathrm{~min}$ ). Slices were immediately frozen on dry ice and then homogenized in lysis buffer (3\% SDS, 20 mm Tris-Cl, pH 7.5, 10 mm EGTA, 40 mm $\beta$-glycerophosphate, $2.5 \mathrm{~mm} \mathrm{MgCl}_{2}$, and Protease Inhibitor Complete) and boiled for $3 \mathrm{~min}$. Western blots were performed as described above.

Statistics. Raw data are presented as averages \pm SEs of the mean (SEM), with $n$ indicating the number of experiments, as stated. Data sets that report percentage changes from control values are expressed as geometric means (GM) to avoid a statistical phenomenon in which the averages of ratios tend to be overestimates. The GM was calculated as the $n$th root of the product of the percentage changes from the control values: 


$$
\mathrm{GM}=\left(\prod_{i=1}^{N} x_{i}\right)^{N^{-1}}
$$

The SE of the geometric mean (SEGM) was calculated by multiplying the GM by the SE of the arithmetic mean of the logarithms of the percentage changes from the control values:

$$
\mathrm{SEGM}=\left(\left(\prod_{i=1}^{N} x_{i}\right)^{N^{-1}}\right)\left(\frac{1}{N} \sum_{i=1}^{N}\left(\log _{10} x_{i}-\log _{10} \bar{x}\right)\right)^{2^{-1}} .
$$

Statistical analyses of two groups were measured using Student's $t$ tests (two-tailed). One-sample $t$ tests (two-tailed) were used to determine whether data sets that were normalized to matched control values were significantly different from $100 \%$. Statistical analyses of data containing more than two groups were performed using the one-way ANOVA test, followed by Tukey-Kramer analysis, to account for multiple comparisons. The Kolmogorov-Smirnov method was used to assess whether data sets had Gaussian distributions, as required for $t$ tests and ANOVA analyses. In cases where the data were not Gaussian, nonparametric tests were used as stated.

\section{Results}

\section{SynGAP regulates spine morphology in vivo}

The results of Vazquez et al. (2004) in cultured neurons suggested that brains of adult $\operatorname{syn} G A P^{+/-}$mice might have larger spines than those of wild-type littermates. To test this hypothesis, we crossed syn $G A P^{+/-}$mice with homozygous GFP line-M transgenic mice $\left(G F P^{+/+}\right)$. In line-M mice, individual neurons and their spines can be visualized easily because they express GFP in a sparse "golgi"-like pattern in CA1 pyramidal neurons (Feng et al., 2000). We acquired confocal images of fluorescent basal dendrites of CA1 pyramidal neurons in littermates, with the investigator blind to the genotype. Three-dimensional images of the dendrites were deconvolved from z-stacks, and spine morphology was analyzed using 3DMA software as described under Materials and Methods (Koh et al., 2002) (supplemental Fig. S1, available at www.jneurosci.org as supplemental material).

Spines are traditionally classified into three categories observed in ultrastructural studies: thin spines have a defined head attached by a thin neck; stubby spines lack necks; while mushroom spines are characterized by large, bulbous heads (Peters and Kaiserman-Abramof, 1970). We found that adult hippocampal neurons from syn $G A P^{+/-}$mice had $19 \%$ more mushroomshaped spines than wild-type neurons (Fig. $1 A, D$ ). The spine head volume (Fig. $1 B$ ) and length (Fig. $1 C$ ) of mushroom spines was also significantly greater in syn $G A P^{+/-}$mice. We found no differences in the morphologies of stubby or thin spines between the two genotypes. These results show that loss of a single copy of the synGAP gene is sufficient to perturb spine morphology and produce an excess of mushroom-shaped spines on adult neurons. They demonstrate that synGAP plays a rate-limiting role in regulation of spine morphology in adult mice.

\section{Steady-state Ras and Rac activity is elevated in adult synGAP $^{+/-}$mice}

Because previous work has demonstrated that Rac is important for spine morphogenesis and maintenance, we tested whether Rac-GTP is altered in brains of adult syn $G A P^{+/-}$mice. We measured the steady-state levels of both Ras- and Rac-GTP in forebrain homogenates from adult syn $G A P^{+/-}$and wild-type mice. Ras-GTP was pulled down on agarose beads conjugated with Raf-1 binding domain. Rac-GTP was pulled down on beads conjugated with PAK binding domain (as described in Materials and
Methods). The pull-down products were separated by SDSPAGE and blotted with either anti-pan-Ras or anti-Racl antibodies. We found that brain homogenates from synGAP ${ }^{+/-}$mice had nearly a twofold increase in Ras-GTP over wild type (Fig. $1 E$ ), as was expected because synGAP downregulates Ras activity. However, we also detected a smaller but significant increase $(32 \%)$ in Rac-GTP in the mutants (Fig. $1 F$ ). SynGAP has not been shown to stimulate Rac-GTP hydrolysis directly and its sequence does not predict that it interacts with Rac. However, there are at least two mechanisms whereby Ras-GTP could indirectly stimulate the activation of Rac. Ras-GTP can bind to and activate the RacGEF, Tiam1, in vitro (Lambert et al., 2002). Tiam1 is present in spines and has been shown to play a role in NMDA receptor-mediated regulation of Rac (Tolias et al., 2005). Alternatively, Ras-GTP can lead to the activation of PI3 kinase which is known to activate several Rac-GEFs, including Tiam1 and kalirin-7, a second PSD-associated RacGEF (Penzes et al., 2000; Xie et al., 2007). Whatever the mechanism, our data show that a $50 \%$ reduction in the level of synGAP in the forebrain leads to a steady-state increase in the amount of activated Rac.

\section{The steady-state level of phospho-cofilin is elevated in adult synGAP ${ }^{+/-}$mice}

Because activation of Rac can lead to phosphorylation and inactivation of cofilin via a cascade of protein kinases, we tested whether the elevation in Rac-GTP measured in syn $G A P^{+/-}$forebrain was associated with a higher steady-state level of phosphorylation of cofilin. Individual forebrains from adult wild-type and syn $G A P^{+/-}$littermates were homogenized, separated by SDSPAGE, and immunoblotted with anti-cofilin and anti-phosphocofilin antibodies. We found a significant increase in the proportion of cofilin that is phosphorylated in crude homogenates from $\operatorname{syn} G A P^{+/-}$mice compared with wild type (Fig. $1 G$ ). These data demonstrate that a $50 \%$ reduction of the level of synGAP in the forebrain leads to an increase in the steady-state level of phosphorylated, inactivated cofilin. This alteration in cofilin phosphorylation would be expected to produce a net increase in actin polymerization over time and a shift toward larger spine heads, as observed in the synGAP $P^{+/-}$neurons shown in Figure 1, $A$ and $D$.

\section{Activation of NMDA receptors transiently modulates the PAK-LIMK-cofilin pathway}

To investigate whether synGAP is important for NMDA receptor-dependent regulation of cofilin activity, we examined the response of the cofilin phosphorylation pathway during application of NMDA to neurons cultured from hippocampus or cortex of wild-type mice. We performed these experiments in cultured neurons because they are more accessible to pharmacological manipulations than whole brain or brain slices. We monitored transient changes in several components of the postulated forward regulatory pathway (see Fig. $3 A$ ), including autophosphorylation of CaMKII, phosphorylation of synGAP by CaMKII, activation of Ras, Rac, and of the Rac effectors PAK and cofilin.

We showed previously that CaMKII phosphorylates three sites on synGAP, producing an increase in its Ras GAP activity (Oh et al., 2004). Here, we found that one of these sites, ser-1123, is phosphorylated under basal conditions in cultured cortical neurons (Fig. 2A). The basal phosphorylation of this site likely arises from baseline NMDA receptor activity because exposure of untreated cultures to calcium-free medium, and to the NMDA receptor blocker MK-801 abolished this phosphorylation (Fig. $2 A)$. The calmodulin inhibitor $\mathrm{W} 7$, and inhibitors of $\mathrm{Ca}^{2+} / \mathrm{CaM}-$ 

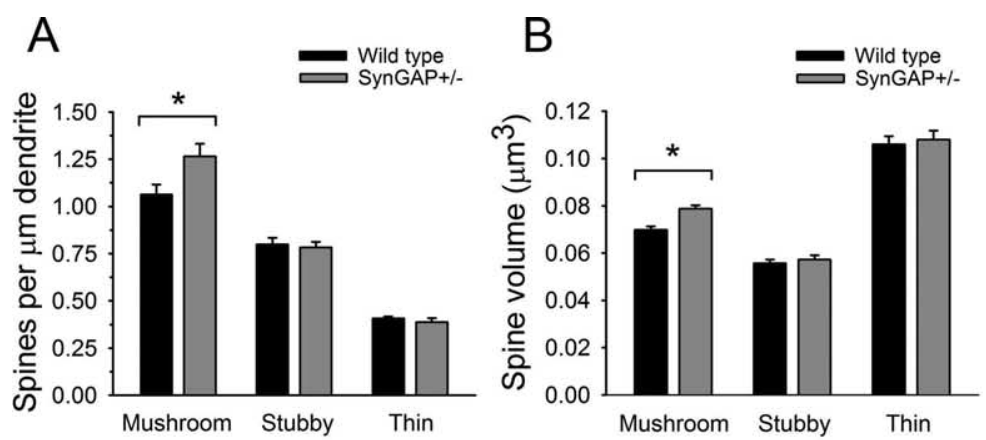

D Wild type
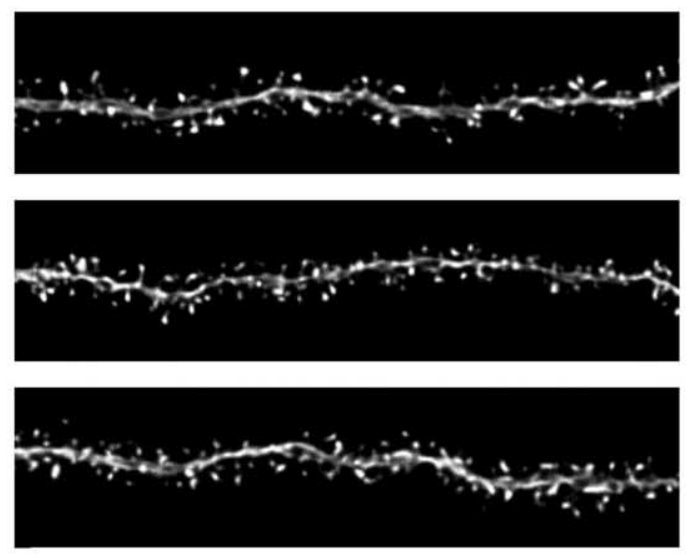

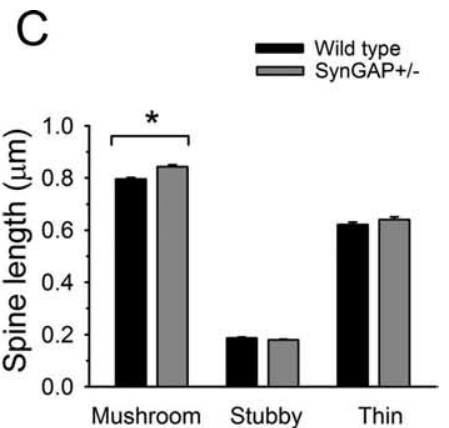

SynGAP +/-
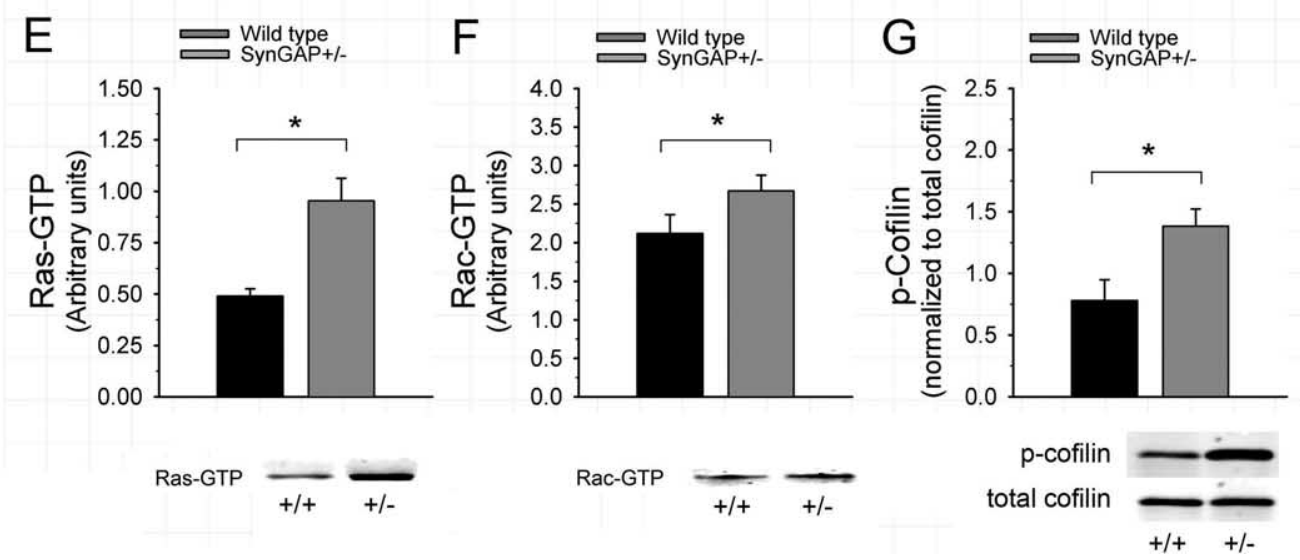

Figure 1. Heterozygous synGAP deletion increases the number of mushroom spines on adult hippocampal CA1 neurons in vivo, increases steady-state activation of Ras and Rac, and decreases steady-state activation of cofilin. $A$, The data show a significant increase (19\%) in the number of mushroom-shaped spines per micrometer of dendrite on synGAP $+/-$ hippocampal neurons compared with wild type (wt) $[\mathrm{wt}=1.06 \pm 0.07$ spines/ $\mu \mathrm{m}$ dendrite; heterozygous (het) $=1.27 \pm 0.05$ spines $/ \mu \mathrm{m}$ dendrite; $p=0.038 ;$ one-tailed Student'st test; $n=3$ wt, 3 het mice]. There is no difference in the density of stubby (wt $=0.799 \pm 0.034$ spines $/ \mu \mathrm{m}$ dendrite; het $=0.782 \pm 0.030$ spines $/ \mu \mathrm{m}$ dendrite) or thin spines (wt $=0.407 \pm 0.009$ spines $/ \mu \mathrm{m}$ dendrite; het $=$ $0.387 \pm 0.022$ spines $/ \mu \mathrm{m}$ dendrite). $\boldsymbol{B}$, The volume of synGAP ${ }^{+/}$mushroom spines is significantly larger than wild-type mushroom spines (wt mushroom $=0.070 \pm 0.001 \mu \mathrm{m}^{3}$, het mushroom $=0.079 \pm 0.005 \mu \mathrm{m}^{3}, p=0.002$, Mann-Whitney Rank Sum Test, $n=2383$ wt, 2788 het mushroom spines; wt stubby $=0.056 \pm 0.002 \mu \mathrm{m}^{3} ;$ het stubby $=0.057 \pm 0.003 \mu \mathrm{m}^{3}$; wt thin $=0.106 \pm 0.012 \mu \mathrm{m}^{3}$; het thin $=0.108 \pm 0.011 \mu \mathrm{m}^{3}$ ). C, SynGAP ${ }^{+/-}$mushroom spines were also significantly longer than wild-type mushroom spines (wt mushroom $=0.797 \pm$ $0.029 \mu \mathrm{m}$, het mushroom $=0.849 \pm 0.034 \mu \mathrm{m}, p=0.001$, Mann-Whitney Rank Sum Test, $n=2383$ wt, 2788 het mushroom spines; wt stubby $=0.187 \pm 0.002 \mu \mathrm{m}$, het stubby $=0.179 \pm$ $0.001 \mu \mathrm{m}$; wt thin $=0.622 \pm 0.022 \mu \mathrm{m}$, het thin $=0.639 \pm 0.025 \mu \mathrm{m}) . \boldsymbol{D}$, Example dendrites are shown from synGAP $P^{+/+} / G F P^{+/-}$and synGAP $P^{+/} /$GFP $^{+/}-$mice. E, The level of Ras-GTP in synGAP $P^{+/-}$forebrains was approximately twofold greater than in wild type [wt $=0.49 \pm 0.04$, het $=0.95 \pm 0.11$ arbitrary units (a.u.); $p=0.016$, two-tailed $t$ test; $n=3$ wt, 3 het mice]. $\boldsymbol{F}$, The level of Rac-GTP in synGAP $P^{+\prime-}$ forebrains was $\sim 30 \%$ higher than in wild type (wt $=2.15 \pm 0.46$, het $=2.58 \pm 0.41$ a.u; $p=0.005$, paired two-tailed $t$ test; $n=7$ wt, 7 het mice). $\boldsymbol{G}$, Steady-state phosphorylation of cofilin was $\sim 75 \%$ higher in synGAP $P^{+\prime-}$ crude forebrain homogenate than in wild type (wt $=0.779 \pm 0.169$, het $=1.38 \pm 0.138, p=0.0122$, paired two-tailed $t$ test, $n=5$ wt, 5 het mice). Bottom in $\boldsymbol{E}, \boldsymbol{F}$, and $\mathbf{G}$ show example blots. Error bars represent SEM.

dependent protein kinases, K252a and KN93, also reduced or abolished the basal phosphorylation (Fig. 2 B), consistent with the hypothesis that basal phosphorylation is due to NMDARdependent activation of CaMKII. These data indicate that the Ras
GAP activity of synGAP is relatively high under basal conditions. Nevertheless, a 15 s treatment with NMDA (25 or $250 \mu \mathrm{M})$ stimulated additional phosphorylation of ser-1123 over basal levels in both cortical and hippocampal cultured neurons (Figs. 2C, 3C). 
A p-SynGAP
SynGAP C $\quad-\left[\mathrm{Ca}^{2+}\right]_{\circ} \mathrm{MK} 801$ W7

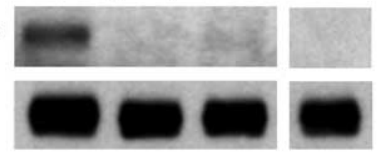

B
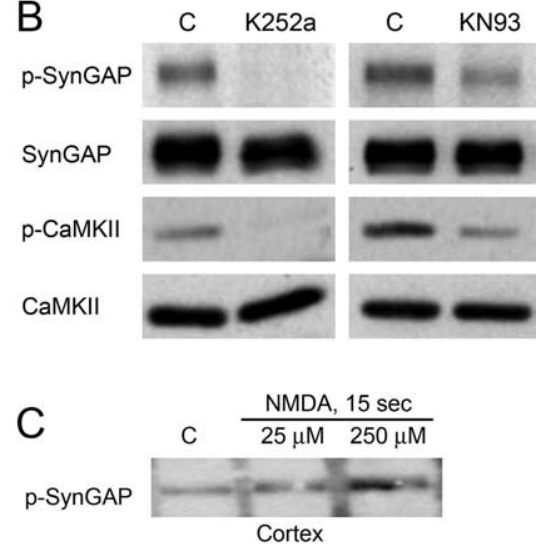

p-SynGAP
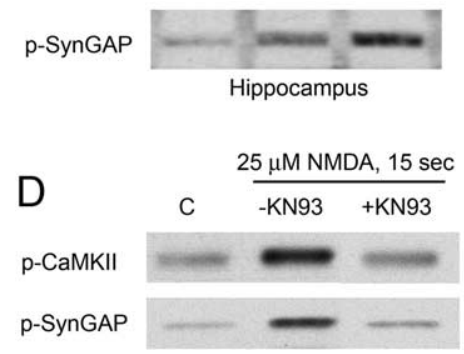

Figure 2. SynGAP is phosphorylated by CaMKII in response to NMDA receptor activation. Experiments were performed on wild-type cortical or hippocampal neuronal cultures after 15-18 DIV. A, SynGAP is basally phosphorylated on Ser ${ }^{1123}$ in untreated wild-type cortical cultures. The phosphorylation is abolished when cultures are incubated in calcium-free medium $\left(-\left[\mathrm{Ca}^{2+}\right]_{\mathrm{e}}\right)$, the NMDAR open-channel blocker MK801 $(10 \mu \mathrm{m})$, or the calmodulin antagonist W-7 $(100 \mu \mathrm{M})$ for $30 \mathrm{~min}(9.7,13.7$, and $0.2 \%$ of control, respectively). $\boldsymbol{B}$, Basal phosphorylation of both synGAP and CaMKII are abolished by a 30 min incubation in $1 \mu \mathrm{m}$ K252a, a general calmodulin-dependent protein kinase inhibitor (3.5 and 1.9\% of control, respectively), and reduced by incubation with $5 \mu \mathrm{M}$ KN-93, a specific inhibitor of CaMKII (39.6 and 30.8\% of control, respectively). Incubation in $10 \mu \mathrm{M} \mathrm{KN}-93$ did not further reduce the level of phosphorylation (38.2\% of control p-SynGAP and 30.8\% of control p-CaMKII). C, Regulation of phosphorylation of synGAP (ser-1123) by activation of NMDA receptors was identical in hippocampal and cortical cultures. A $15 \mathrm{~s}$ application of $25 \mu \mathrm{M}$ NMDA or $250 \mu \mathrm{M}$ NMDA stimulated phosphorylation of synGAP above control levels $(25 \mu \mathrm{M}=188 \%$ and $250 \mu \mathrm{M}=364 \%$ of control hippocampal phospho-synGAP; $25 \mu \mathrm{M}=243 \%$ and $250 \mu \mathrm{M}=398 \%$ of control cortical phosphosynGAP). D, In cortical cultures, phosphorylation of CaMKII and synGAP stimulated by a $15 \mathrm{~s}$ application of NMDA $(25 \mu \mathrm{m})$ was blocked by the CaMKII inhibitor KN-93 (10 $\mu \mathrm{M})$ (NMDA alone $=355 \%$ of control phospho-synGAP and $576 \%$ of control phospho-CaMKIl; NMDA + KN-93 $=151 \%$ of control phospho-synGAP and $177 \%$ of control phospho-CaMKII). Experiments were performed three times with similar results, except for those in part $\boldsymbol{D}$, which were performed twice with similar results.

As expected, this additional phosphorylation was also blocked by the CaMKII inhibitor, KN93 (Fig. 2D).

To measure the time course of activation of CaMKII, synGAP, Ras, and Rac by the NMDA receptor, we treated wild-type cortical or hippocampal cultures with NMDA $(25 \mu \mathrm{M})$ for various times. Autophosphorylation of thr-286 on CaMKII, which activates its kinase activity, was significantly increased within the first $15 \mathrm{~s}$ of treatment (Fig. 3B,E). Phosphorylation of ser-1123 on synGAP by CaMKII was also increased within $15 \mathrm{~s}$ of treatment with NMDA (Fig. 3C,E). However, its level of phosphorylation returned to baseline after a 3 min treatment, and was significantly below baseline after a 5 min treatment. Ras was activated within $15 \mathrm{~s}$ of NMDA treatment, almost completely inactivated after 1 min, and back to baseline after a 3 min treatment (Fig. $3 D, E$ ). The peak phosphorylation of synGAP preceded inactivation of Ras, consistent with the notion that synGAP participates in inactivation of Ras following activation of NMDA receptors. Together, the data in Figures 2 and 3 show that stimulation of NMDA receptors in cultured neurons results in activation of both Ras and CaMKII. They support the hypothesis that, upon activation of NMDA receptors, phosphorylation of synGAP by activated CaMKII maintains synGAP in a highly active state which helps to restrict the length of time over which Ras remains activated.

The second limb of the cofilin phosphorylation pathway (Fig. $3 A$ ) was also transiently modulated in response to activation of NMDA receptors (Fig. $3 E-H$ ). Activated Rac can bind and activate PAK, which in turn phosphorylates and activates LIMK (Arber et al., 1998; Yang et al., 1998; Edwards et al., 1999). LIMK then inactivates cofilin by phosphorylating ser-3, which prevents cofilin from binding to and severing F-actin. Activation of Rac was evident $1 \mathrm{~min}$ after application of NMDA to wild-type hippocampal cultures. The delay in its activation relative to that of Ras is consistent with a requirement for several enzymatic steps between activation of the NMDA receptor and activation of Rac (Fig. 3F). Phosphorylation of thr-423 in $\operatorname{PAK}(1-3)$, which is autophosphorylated in active PAK, was increased by more than twofold $15 \mathrm{~s}$ after application of NMDA, suggesting that Rac activation is not critical for rapid activation of PAK1-3 (Fig. $3 E, G)$. Cdc42 can also activate PAK (Manser et al., 1994) and, thus, may play a role in the NMDA-dependent activation of PAK. Although a major downstream target of PAK is LIMK, which phosphorylates cofilin (Edwards et al., 1999), we found that NMDA caused a rapid $40 \%$ reduction in phospho-cofilin followed by a slow recovery of phosphorylation (Fig. $3 E, H$ ). This result means that activation of NMDA receptors rapidly initiates transient dephosphorylation of cofilin even while PAK is being activated. This transient decrease in phosphorylation of cofilin in response to NMDA receptor activation has not been described previously. One candidate cofilin phosphatase that may be activated via the NMDA receptor is slingshot, which is activated by calcineurin, a calcium-regulated phosphatase (Wang et al., 2005). Slingshot is capable of dephosphorylating both LIMK and cofilin (Niwa et al., 2002; Soosairajah et al., 2005; Wang et al., 2005), however its regulation in neurons has not been studied.

\section{NMDA receptor-dependent transient modulation of cofilin is} disrupted in synGAP ${ }^{-1-}$ neurons

We next asked whether the reduction of synGAP in neurons cultured from syn $G A P^{-/-}$or syn $G A P^{+/-}$embryos alters the steadystate levels of active PAK and cofilin or their transient responses to activation of the NMDA receptor. As in brains of adult syn$G A P^{+/-}$mice, steady-state levels of phosphorylated PAK and cofilin were significantly elevated under basal conditions in hippocampal cultures from synGAP${ }^{-1-}$ embryos (Fig. 4A). Although the basal levels of phosphorylated PAK were significantly higher in the synGAP${ }^{-/-}$cultures, the percentage increase in phosphorylation after treatment with NMDA was similar to wild type (Fig. $4 B$ ). However, the transient dephosphorylation of cofilin after treatment with NMDA was reduced in $\operatorname{syn} G A P^{+/-}$ neurons and completely abolished in synGAP ${ }^{-1-}$ neurons (Fig. $4 C$ ). Because dephosphorylation of cofilin activates its actinsevering activity, these data suggest that, in synGAP mutant neurons, the postsynaptic actin cytoskeleton may be resistant to 
activity-dependent transient depolymerization of actin triggered by NMDA receptors. The mechanism underlying this defect in transient dephosphorylation of cofilin is distinct from the mechanism underlying the elevation of steady-state phosphorylation of cofilin in synGAP mutant brains that likely accounts for the increased number of mushroom spines.

Depression of EPSP amplitude caused by application of NMDA to hippocampal slices is altered in slices from synGAP ${ }^{+/-}$mutants

Bath application of NMDA has been shown to increase AMPA receptor internalization in cultured neurons (Ehlers, 2000) and induce LTD of EPSPs in hippocampal slices from mice younger than 3 weeks old (Lee et al., 1998). In slices from older mice, a similar depression of EPSP amplitude can be induced by a 5 min application of $25 \mu \mathrm{M}$ NMDA if the concentration of calcium in the ACSF is increased from 2 to $4 \mathrm{~mm}$ (Norris et al., 1996). Because we found that transient dephosphorylation of cofilin produced by a $5 \mathrm{~min}$ application of NMDA to neuronal cultures is absent in neurons from synGAP $P^{+/-}$ mice, we asked whether depression of EPSPs produced by a 5 min application of NMDA to hippocampal slices from 6-week-old mice is altered by the syn$G A P^{+/-}$mutation.

Consistent with previous studies (Norris et al., 1996), we found that a 5 min application of NMDA in ACSF containing $4 \mathrm{mM} \mathrm{Ca}^{2+}$ (high-Ca ${ }^{2+}$ ACSF) induced a long-lasting depression in hippocampal slices from wild-type mice (Fig. 5A). However, the same protocol applied to $\operatorname{syn} G A P^{+/-}$slices induced a transient depression of lower magnitude, which returned to baseline after 35 min (Fig. 5A). Previous studies have shown that NMDA receptor function is normal in synGAP ${ }^{+1-}$ mice (Komiyama et al., 2002). Therefore, our results indicate that heterozygous deletion of synGAP disrupts a mechanism by which application of NMDA can lead to a longlasting depression of EPSPs.

To investigate how phosphorylation of cofilin was affected by application of NMDA to slices for $5 \mathrm{~min}$, we measured the level of phospho-cofilin in the slices 2 min before NMDA treatment and 0,5 , 10 , and $15 \mathrm{~min}$ after the end of the $5 \mathrm{~min}$ NMDA treatment (Fig. $5 B, C$ ). We did not attempt to measure the transient response of p-cofilin to brief treatments with NMDA for 0.25 or $1 \mathrm{~min}$ because its penetration into the slices is slow and
A

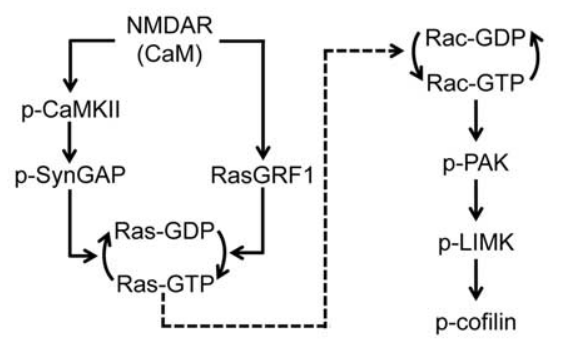

$\mathrm{B}$

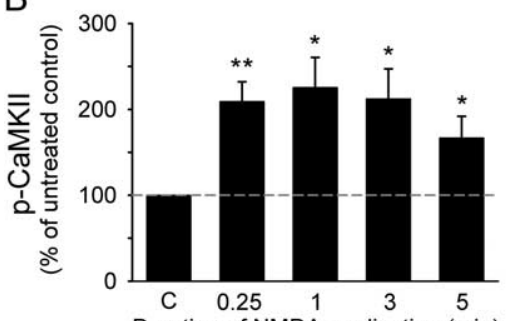

C

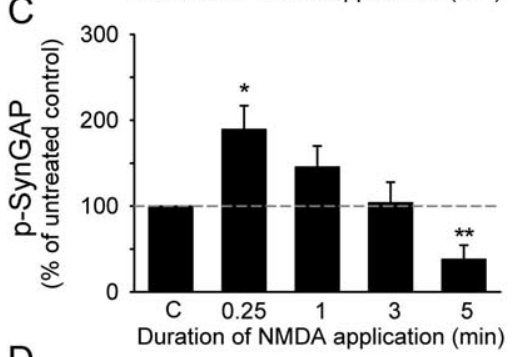

$\mathrm{D}$

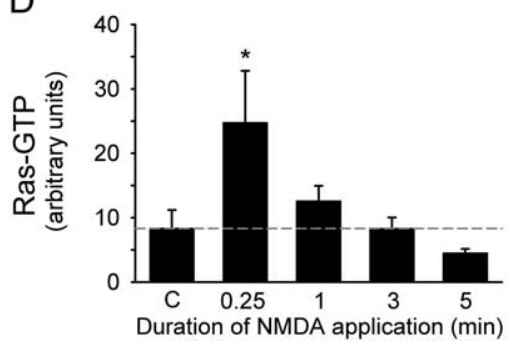

E

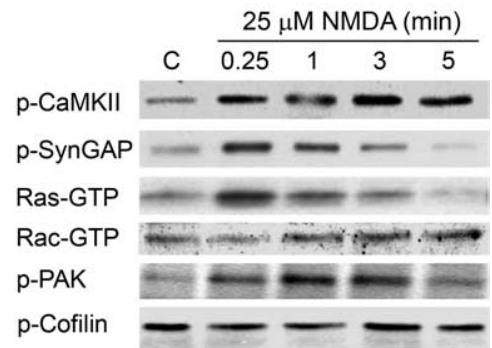

$\mathrm{F}$

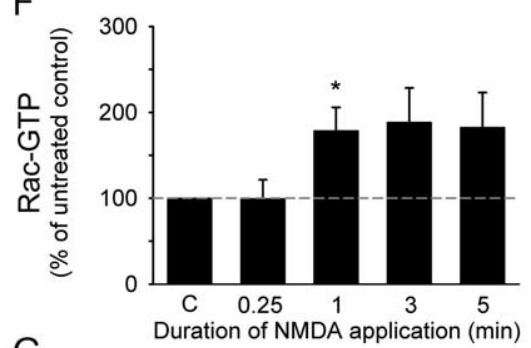

G

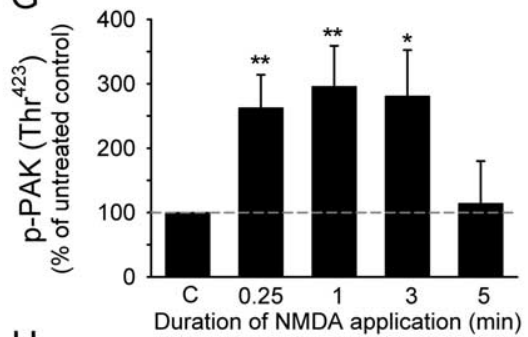

$\mathrm{H}$

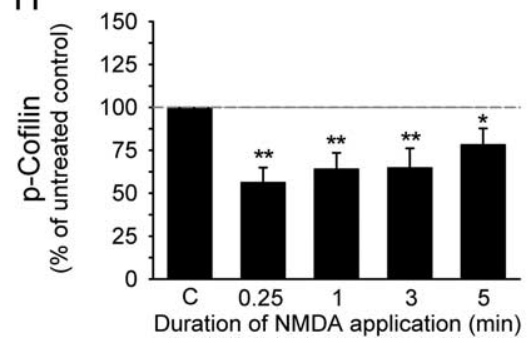

Figure 3. Bath application of NMDA in neuronal cultures increases the phosphorylation of CaMKII and synGAP, the activation of Ras and Rac, and the phosphorylation of PAK, but causes a decrease in the phosphorylation of cofilin. $A$, The diagram depicts one postulated pathway through which the NMDA receptor regulates Ras activity (left) and the Rac-dependent pathway that regulates cofilin (right). The dotted line represents a hypothetical link between activated Ras and activated Rac that is suggested by our data. Wild-type cortical or hippocampal neurons were treated with NMDA ( $25 \mu \mathrm{M})$ for $0.25,1,3$, or 5 min. Phosphorylation of CaMKII, synGAP, PAK, and cofilin, and activation of Ras and Rac were measured as described in Materials and Methods. $\boldsymbol{B}, \boldsymbol{E}$, Samples from cortical and hippocampal cultures that were immunoblotted with anti-phospho-Thr ${ }^{286}$ CaMKII antibody showed a significant increase in phosphorylation within $15 \mathrm{~s}$ of treatment with NMDA $\left(15 \mathrm{~s}^{*}=209 \pm 23 \%, p=0.009 ; 1 \mathrm{~min}^{*}=225 \pm\right.$ $35 \%, p=0.016 ; 3 \mathrm{~min}^{*}=212 \pm 35 \%, p=0.023 ; 5 \mathrm{~min}^{*}=167 \pm 25 \%$ of untreated control, $p=0.046 ;$ one-sample $t$ test, data from cortical and hippocampal cultures were combined, $n=6$ independent experiments). $\boldsymbol{C}$, $\boldsymbol{E}$, Samples from cortical and hippocampal cultures immunoblotted with anti-phospho-Ser ${ }^{1123}$ synGAP antibody showed a significant increase in phosphorylation of ser-1123 on synGAP by CaMKII after 15s, followed by rapid dephosphorylation $\left(15 \mathrm{~s}^{*}=189 \pm 28 \%, p=0.01 ; 1 \mathrm{~min}=\right.$ $146 \pm 24 \% ; 3 \min =104 \pm 24 \% ; 5 \mathrm{~min}^{*}=38.1 \pm 16 \%$ of untreated control, $p=0.004$; two-tailed one-sample $t$ test; data from cortical and hippocampal cultures were combined, $n=10$ independent experiments). $\boldsymbol{D}, \boldsymbol{E}$, Activated Ras was measured in homogenates of hippocampal and cortical cultures as described under Materials and Methods. Treatment with NMDA (25 $\mu \mathrm{M})$ induced brief activation of Ras [control $=8.32 \pm 2.88$ arbitrary units (a.u.); $15 \mathrm{~s}^{*}=24.8 \pm 8.0$ a.u., $p=0.018 ; 1 \mathrm{~min}=12.6 \pm$ 2.4 a.u.; $3 \mathrm{~min}=8.31 \pm 1.71$ a.u.; $5 \mathrm{~min}=4.50 \pm 0.64$ a.u.; repeated measures $A N O V A ; n=3$ independent experiments]. $\boldsymbol{F}$, $\boldsymbol{E}$, Activated Rac measured from hippocampal and cortical cultures is significantly elevated after 1 min treatment with NMDA (25 $\mu \mathrm{m}$ ) compared with untreated controls $\left(0.25 \mathrm{~min}=109 \pm 19.8 \% ; 1 \mathrm{~min}^{*}=183 \pm 22.3 \%, p=0.048\right.$, two-tailed one-sample $t$ test; $3 \mathrm{~min}=207 \pm 58.7 \% ; 5 \mathrm{~min}=204 \pm 54.3 \%$ of control; $n=5) . \boldsymbol{G}, \boldsymbol{E}$, Anti-phospho-Thr ${ }^{423}$ PAK was elevated more than twofold in the first $15 \mathrm{~s}$ of treatment with NMDA $\left(15 \mathrm{~s}^{*}=267 \pm 46.4 \%, p=0.009 ; 1 \mathrm{~min}^{*}=294 \pm 54.7 \%, p=0.009 ; 3 \mathrm{~min}^{*}\right.$ $=286 \pm 63.7 \%, p=0.022 ; 5 \mathrm{~min}=132 \pm 67.5 \%$; two-tailed, one sample $t$ test; $n=8$ independent experiments). $\boldsymbol{H}, \boldsymbol{E}$ Anti-phospho-Ser ${ }^{3}$ cofilin was dephosphorylated in response to treatment with NMDA for $15 \mathrm{~s}$ to $5 \mathrm{~min}\left(15 \mathrm{~s}^{*}=56.2 \pm 8.68 \%\right.$, $p>0.001 ; 1 \mathrm{~min}^{*}=64.2 \pm 9.37 \%, p=0.005 ; 3 \mathrm{~min}^{*}=64.8 \pm 11.3 \%, p=0.001 ; 5 \mathrm{~min}^{*}=78.3 \pm 9.46 \%, p=0.047$; two-tailed, one-sample $t$ test; $n=10$ independent experiments). Representative immunoblots are shown in $\boldsymbol{E}$. $\boldsymbol{D}$ shows means \pm SEM $\boldsymbol{B}, \boldsymbol{C}, \boldsymbol{F}, \boldsymbol{G}$ and $\boldsymbol{H}$ show $\mathrm{GM} \pm$ SES of the SEGM. 
A

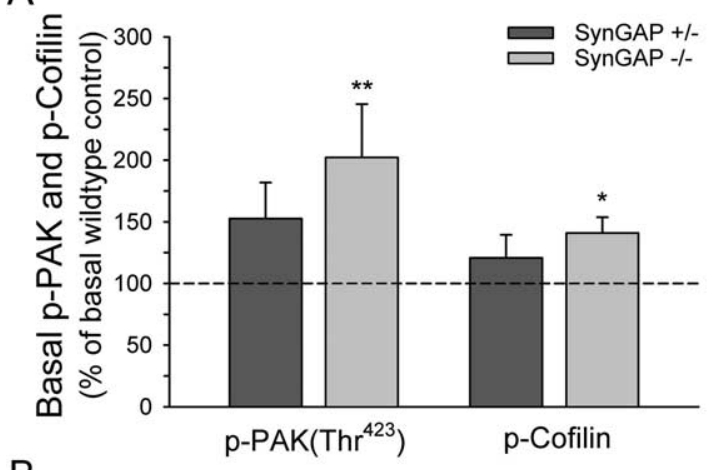

B

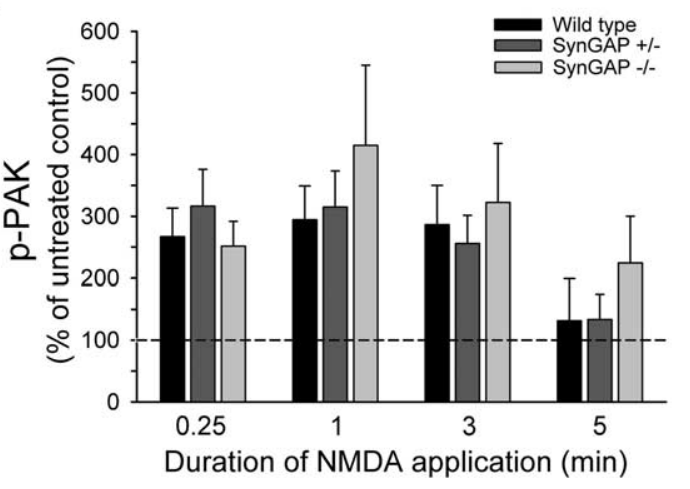

C

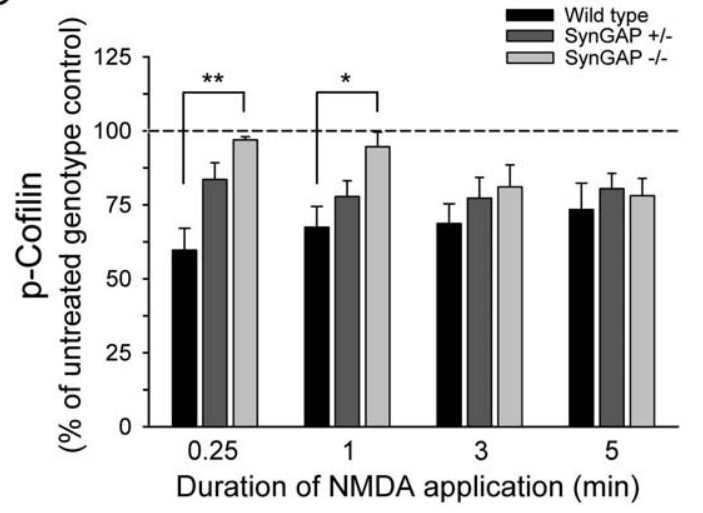

Figure 4. Steady-state activity of PAK and cofilin is altered and regulation cofilin activity by the NMDA receptor is deranged in synGAP mutant hippocampal cultures. Wild-type, synGAP ${ }^{+/-}$, and synGAP ${ }^{-/-}$hippocampal cultures (DIV 15-18) were treated with $25 \mu \mathrm{M}$ NMDA for 15 s to 5 min and then immunoblotted with anti-phospho-Thr ${ }^{423}$ PAK(1-3) or anti-phospho-Ser ${ }^{3}$ cofilin antibody. Phosphoprotein levels were measured and quantified as described under methods. $A$, The levels of phospho-PAK and phospho-cofilin were basally elevated in untreated synGAP-/- hippocampal cultures. Changes in phosphorylation of PAK and cofilin are expressed as a percentage of the wild-type untreated control values (synGAP ${ }^{+/-}$phospho-PAK $=153 \pm 29.2 \%$ of wt, $n=7$ litters; synGAP ${ }^{-\prime-}$ phospho-PAK ${ }^{*}=202 \pm 43.4 \%$ of wt, $p=0.006, n=5$ litters; synGAP ${ }^{+/-}$phospho-cofilin $=$ $121 \pm 18.6 \%$ of wt, $n=11$ litters; synGAP ${ }^{-\prime-}$ phospho-cofilin* $=141 \pm 12.9 \%$ of wt, $p=0.012, n=10$ litters). B, Despite the basal increase in phosphorylated PAK in the mutants, treatment with NMDA still induces an additional increase in phosphoPAK, similar to that in wild types, when each genotype is normalized to its own untreated genotype control (wild type: $15 \mathrm{~s}=$ $267 \pm 46.4 \%, 1 \mathrm{~min}=294 \pm 54.7 \%, 3 \mathrm{~min}=286 \pm 63.7 \%, 5 \mathrm{~min}=132 \pm 67.5 \%$ of wild-type control; $n=8$ litters) $\left(\right.$ SynGAP ${ }^{+\prime-} ; 15 \mathrm{~s}=316 \pm 58.5 \%, 1 \mathrm{~min}=315 \pm 58.4 \%, 3 \mathrm{~min}=256 \pm 45.7 \%, 5 \mathrm{~min}=134 \pm 40.6 \%$ of synGAP $P^{+\prime-}$ control; $n=8$ litters) (SynGAP-l-$; 15 \mathrm{~s}=252 \pm 40.1 \% ; 1 \mathrm{~min}=415 \pm 130 \% ; 3 \mathrm{~min}=322 \pm 95.5 \% ; 5 \mathrm{~min}=224 \pm$ $75.7 \%$ of synGAP ${ }^{-1-}$ control; $n=8$ litters). C, NMDA induces significantly less dephosphorylation of cofilin in synGAP mutant compared with wild-type cultures (wild type: $15 \mathrm{~s}=59.7 \pm 7.37 \% ; 1 \mathrm{~min}=67.4 \pm 7.05 \% ; 3 \mathrm{~min}=68.7 \pm 6.68 \% ; 5 \mathrm{~min}=$ $73.4 \pm 78.91 \%$ of wild-type control; $n=6$ litters) (SynGAP ${ }^{+/-}: 15 \mathrm{~s}=83.5 \pm 5.64 \% ; 1 \mathrm{~min}=77.8 \pm 5.29 \% ; 3 \mathrm{~min}=$ $77.2 \pm 7.04 \% ; 5 \mathrm{~min}=80.4 \pm 5.16 \%$ of SynGAP ${ }^{+/-}$control; $n=4$ litters) (SynGAP ${ }^{-\prime-}: 15 \mathrm{~s}^{*}=96.9 \pm 1.07 \%, p=0.006$; $1 \mathrm{~min}^{*}=94.6 \pm 4.87 \%, p=0.37 ; 3 \mathrm{~min}=81.0 \pm 7.48 \% ; 5 \mathrm{~min}=78.0 \pm 5.85 \%$ of SynGAP ${ }^{-\prime}{ }^{-}$control; $n=5$ litters; one-way ANOVA comparing the three genotypes at each time point, followed by Tukey-Kramer multiple comparison test). All time points were significantly less than $100 \%$ in the wild-type neurons; the 1,3, and 5 min time points were significantly less than $100 \%$ in the synGAP ${ }^{+/-}$neurons; and only the 5 min time point was significantly less than $100 \%$ in the synGAP ${ }^{-1-}$ neurons $(p<0.05$, two-tailed, one-sample $t$ test). Example blots are shown on right. Graphs represent geometric means \pm SEGM. therefore rapid biochemical responses are obscured. At the end of the $5 \mathrm{~min}$ treatment, the phospho-cofilin was slightly reduced in slices from wild-type mice, as it was in cultured neurons (Fig. $4 C)$. In slices from synGAP $P^{+/-}$mice, phospho-cofilin returned to a higher steady-state level than in wild-type slices, during the recovery from the NMDA treatment (Fig. 5B,C).

\section{Discussion}

We have demonstrated that loss of a single copy of the synGAP gene produces a derangement of regulation of actin in spines that is measurable anatomically as a change in spine shape in adult animals. Such gene dosage effects resulting from loss of one copy of a regulatory protein are relatively rare. Most regulatory networks in biology are complex and robust; thus, reduction of a single component by $50 \%$ is often compensated for by adjustment of the activity of other components. The gene dosage effect reveals that regulation of spine shape and the actin cytoskeleton are highly sensitive to the activity of synGAP. Because reduction of synGAP by $50 \%$ has also been shown to measurably alter regulation of AMPA receptor numbers at synapses (Rumbaugh et al., 2006), our data establish that synGAP is a critical common component of two important regulatory pathways at synapses. This gene dosage effect makes the synGAP knock-out mouse a powerful tool for analyzing regulatory mechanisms in the spine. By examining perturbation of the actin regulatory pathway in the synGAP heterozygote, we have confirmed a link between synGAP's regulation of Ras, and the regulation of Rac in spines. Furthermore, we found that activation of NMDA receptors in wildtype neurons causes a rapid and transient dephosphorylation of phospho-cofilin that is uncoupled from regulation of PAK1-3.

An abundance of physiological and behavioral evidence has established that synGAP plays a role in synaptic plasticity and in learning and memory. Deletion of synGAP in mice is lethal by a few days after birth (Komiyama et al., 2002; Kim et al., 2003; Vazquez et al., 2004). However, animals heterozygous for the deletion grow to adulthood. They show a reduced amplitude of hippocampal LTP and their ability to learn the Morris Water Maze is impaired (Komiyama et al., 2002). In hippocampal neurons cultured from embryos with the synGAP deletion, activation of ERK, which is downstream of Ras, is ele- 
A

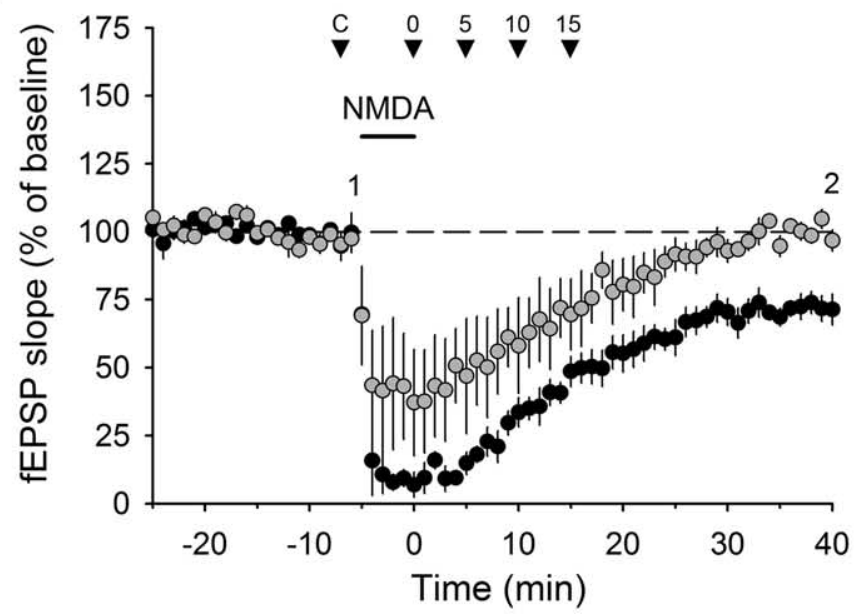

- Wild type

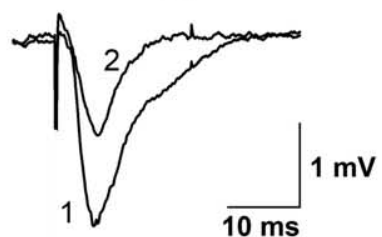

$10 \mathrm{~ms}$
- SynGAP +/-

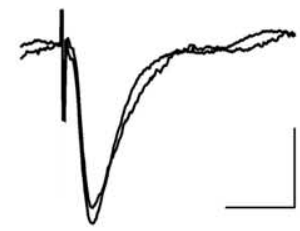

B

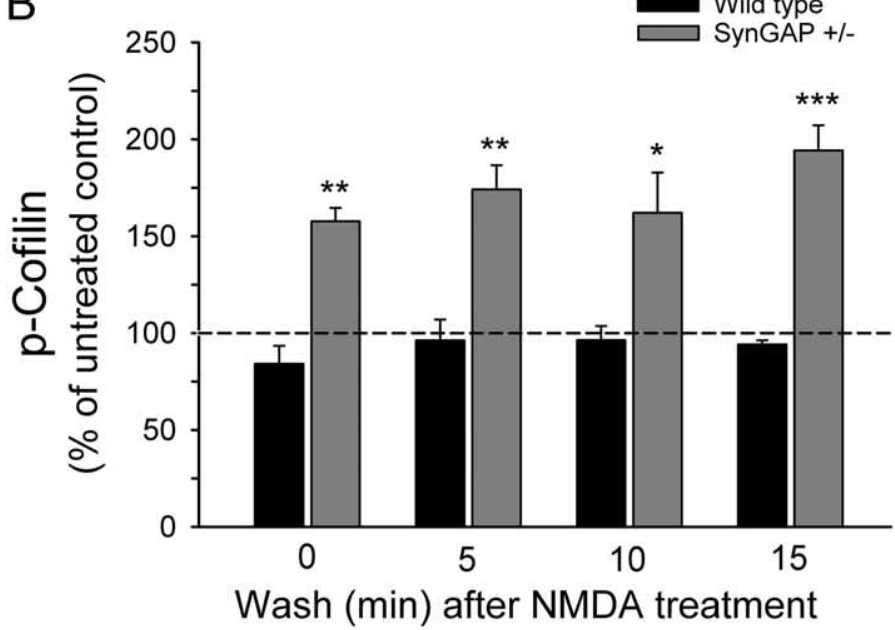

C

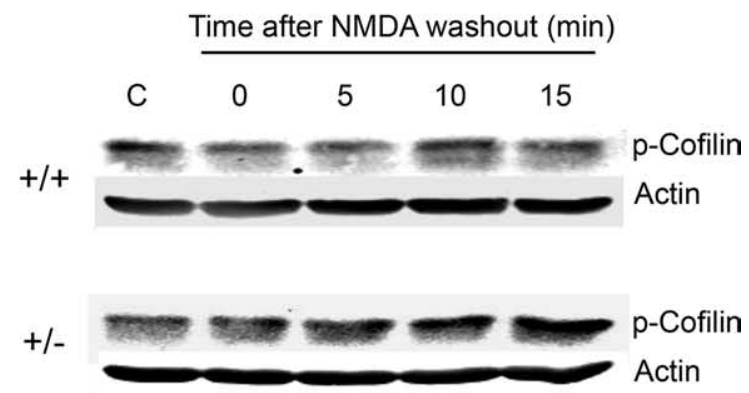

Figure 5. NMDA does not induce long term depression of EPSPs in synGAP ${ }^{+/-}$hippocampal slices. $A$, Bath application of NMDA ( $25 \mu M, 5$ min) induced long-lasting depression of wild-type, but not synGAP ${ }^{+1-}$, EPSPs. Wild-type ESPSs were significantly depressed at 40 min after NMDA was washed out (71 $\pm 6 \%$ of baseline ESPS slope, $p=0.02$, two-tailed, one-sample $t$ test, $n=4$ wt mice). EPSPs in synGAP $P^{+/-}$slices were not significantly different from baseline levels 40 min after NMDA washout (101 $\pm 1 \%$ of baseline EPSP slope, $n=5$ het mice). Example EPSPs at time $=$ $-5 \mathrm{~min}(1)$ and time $=40 \mathrm{~min}(2)$ are shown above. $\boldsymbol{B}$, In a similar set of experiments, wild-type and synGAP ${ }^{+/}$- hippocampal slices were collected for biochemical analysis 2 min before bath application of NMDA (control), immediately after NMDA treatment ( 0 min), and 5, 10, and 15 min after washout of NMDA (as indicated by arrowheads in $A$ ). These slices were homogenized and proteins were immunoblotted with anti-serine ${ }^{3}$-cofilin antibody and anti-actin antibody as described under Materials and Methods. The level of phosphorylated cofilin was normalized to total actin staining. SynGAP ${ }^{+\prime-}$ slices had significantly higher levels of phosphorylated cofilin (normalized to control values) than wild types after treatment with NMDA (0 min* ${ }^{*}$ wt $=84.1 \pm 9.3 \%$, het $=$ $158 \pm 6.9 \%, p=0.002 ; 5 \mathrm{~min}^{*}, \mathrm{wt}=96.2 \pm 10.6 \%$, het $=174 \pm 12.4 \%, p=0.005 ; 10 \mathrm{~min}^{*}$, wt $=96.3 \pm 7.3 \%$, het $=162 \pm 21 \%, p=0.019 ; 15 \mathrm{~min}{ }^{*}$, wt $=94.1 \pm 2.1 \%$, het $=194 \pm$ $12.9 \%$; ${ }^{*} p=0.0003$, two-tailed $t$ test, $n=4$ wt, 3 het mice). $\boldsymbol{C}$, Representative blots from data reported in graph $\boldsymbol{B}$. Error bars are geometric means \pm SEGM.

vated, and insertion of AMPA receptors at synapses is elevated compared with wild type (Kim et al., 2003, 2005; Krapivinsky et al., 2004; Rumbaugh et al., 2006). Studies on cultured mutant neurons have shown that deletion of synGAP alters the time course of spine development and spine morphology in vitro (Vazquez et al., 2004). In the present study, we have shown that spine morphology is altered in brains of adult synGAP ${ }^{+/-}$mice; they have $\sim 20 \%$ more mushroom-shaped spines than wild-type brains. We have illuminated the mechanism underlying this change by showing that synGAP $P^{+/-}$mice have altered steadystate activity of proteins throughout the signaling network that regulates cofilin, an important mediator of actin remodeling during synaptic activity (Carlisle and Kennedy, 2005; Soosairajah et al., 2005; Wang et al., 2005; Chen et al., 2007) (Fig. 6). The altered activities result in a steady-state decrease in the filament-severing function of cofilin that could lead to the observed increase in the number of mushroom spines. The loss of synGAP in homozygotes also alters transient regulation of cofilin by abolishing the normal rapid activation of cofilin in response to activation of NMDA receptors.

Activation of Rac was elevated in syn $G A P^{+/-}$brains, although synGAP itself has no direct action on Rac GTPase activity. SynGAP can regulate activation of both Ras and Rap (Chen et al., 1998; Krapivinsky et al., 2004). It is unlikely that altered Rap activity accounts for the enlargement of spine heads observed on synGAP mutant neurons because inhibition of the specific RapGAP, SPAR, results in the opposite spine phenotype (Pak et al., 2001). The synGAP mutant spine phenotype is more likely due to loss of RasGAP activity which causes an increase in steady-state levels of Ras-GTP and subsequent downstream activation of Rac. Tolias et al. (2005) showed that the RacGEF activity of Tiam1 is activated in spines by the NMDA receptor. These authors at- 


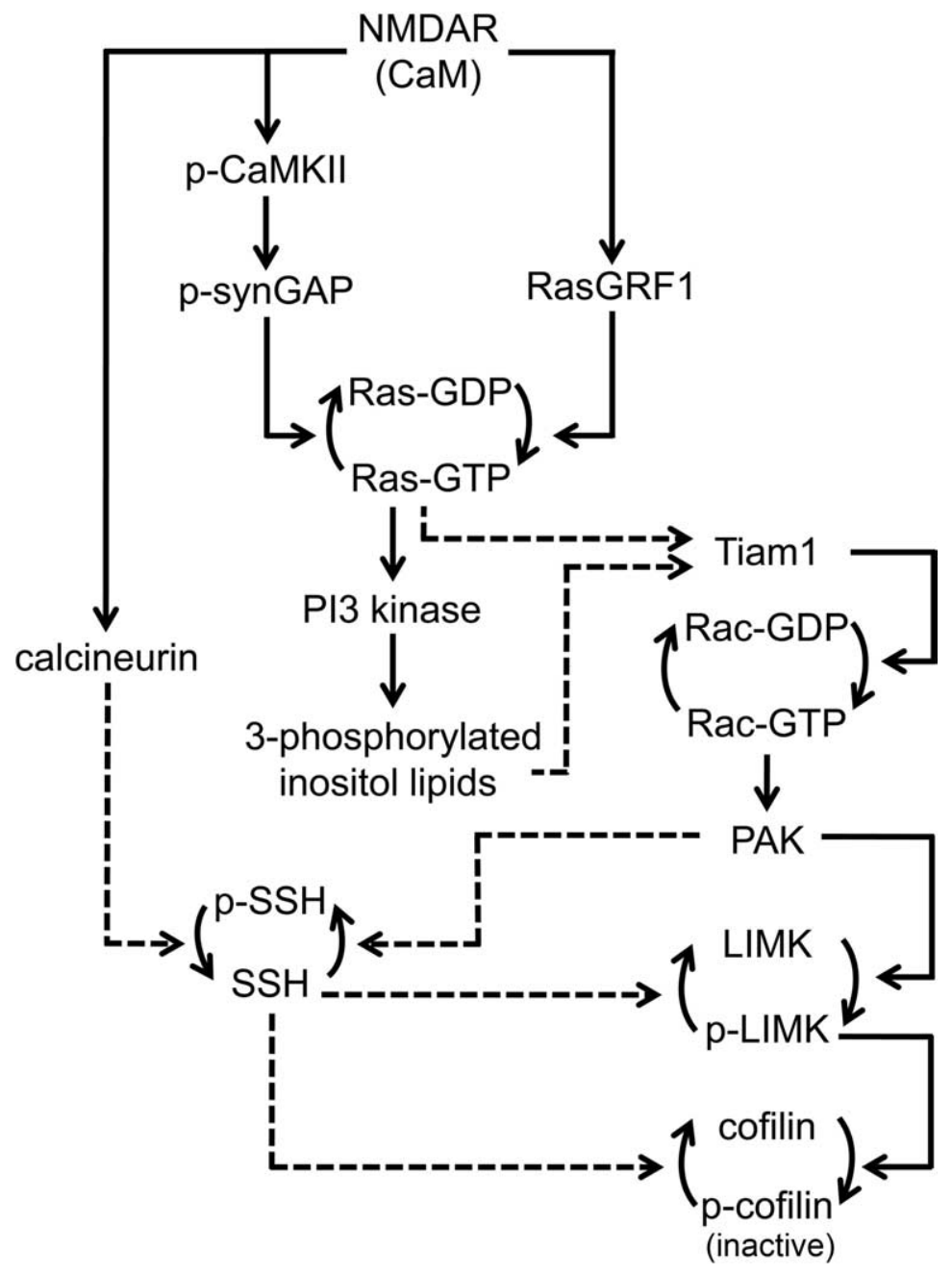

Figure 6. Diagram of regulatory pathways through which synGAP and the NMDA receptor can regulate cofilin activity. Solid lines indicate regulatory interactions that have been shown to occur in spines. Dashed lines indicate regulatory interactions that have been shown to occur in vitro or in non-neuronal cells and that our results suggest also occur in spines. See Discussion for references.

tribute the activation of Tiam 1 to its phosphorylation by CaMKII, which is activated when $\mathrm{Ca}^{2+}$ enters the spine through NMDA receptors. However, Lambert et al. (2002) showed that Ras-GTP can bind directly to Tiam1 and activate its RacGEF activity. Ras can also activate Tiam1 via activation of PI3 kinase which produces polyphosphoinositides that stimulate Tiam1 (Fleming et al., 2004). Thus, the elevated steady-state level of activated Ras that occurs in the absence of synGAP could lead by several mechanisms to the subsequent aberrant activation of Tiam 1 and Rac. Whatever the precise mechanism, our data show that the $50 \%$ reduction of synGAP in heterozygote brains produces a $32 \%$ increase in steady-state activation of Rac. As expected, we also found a steady-state increase in the level of phosphorylation and inactivation of cofilin, which is controlled by the downstream Rac effectors, PAK and LIM kinase (Fig. 6).

The shifting balance between regulatory phosphorylation and dephosphorylation over time sculpts many of the changes that result in alteration of the strength of a synapse. We show that reduction of synGAP also disrupts a transient dephosphorylation and activation of cofilin controlled by the NMDA receptor. One possible mechanistic explanation is found in two recent reports about the regulation of slingshot, a specific cofilin phosphatase. Wang et al. (2005) found that calcineurin dephosphorylates and activates slingshot. Because calcineurin is rapidly activated in spines upon activation of the NMDA receptor (Quinlan and Halpain, 1996), it could rapidly dephosphorylate and activate slingshot, thus accounting for the normal dephosphorylation of cofilin in wild-type neurons. Soosairajah et al. (2005) found that PAK opposes the action of calcineurin by phosphorylating and inactivating slingshot. Thus, the high steady-state activity of PAK in synGAP mutant neurons compared with wild type may lead to abnormally high steady-state phosphorylation of slingshot, counteracting NMDA-induced dephosphorylation of slingshot by calcineurin and abolishing the normal dephosphorylation of cofilin in response to NMDA receptor activation.

How might dysregulation of the spine cytoskeleton in synGAP mutants alter brain function? Live-imaging studies reveal that thin spines are usually transient, whereas mushroom-shaped spines are more stable and can persist for months (Holtmaat et al., 2005; Zuo et al., 2005). Thin spines also more readily undergo LTP with a concurrent growth in the spine head, while mushroom spines are less responsive to LTP-inducing stimuli (Matsuzaki et al., 2004). These observations have lead to the hypothesis that thin spines are "learning" spines and mushroom spines represent "memory" spines (Bourne and Harris, 2007). Our study shows that Syn$G A P^{+/-}$mice have significantly more mushroom-shaped spines in the CA1 region of the hippocampus than wild-type mice. This finding suggests that synGAP normally acts to downregulate signaling pathways that promote growth of spine heads, perhaps helping to maintain spines in an appropriately plastic state. A high steady-state level of phosphorylated, inactivated cofilin would increase the stability of the elaborated actin cytoskeleton in mushroom spines. Furthermore, the suppression in synGAP mutants of transient activation of cofilin by NMDA receptors would make cytoskeletal structures within the spine head relatively resistant to activity-dependent remodeling. All of these changes are predicted to disrupt normal synaptic plasticity.

Indeed, we found that a long-lasting depression of the EPSP, induced by bath application of NMDA, was disrupted in syn$G A P^{+/-}$hippocampal slices. One possible explanation for this disruption is that NMDA receptor-induced activation of cofilin and depolymerization of a particular actin pool may be necessary to permit sufficient removal of AMPA receptors to produce longlasting depression of EPSPs. Inhibition of actin depolymerization has been shown in some studies to block AMPA receptor internalization and LTD induced by low frequency stimulation (Zhou et al., 2001; Wang et al., 2007). Others have reported that the inclusion of peptide inhibitors of cofilin in the whole-cell recording pipette does not block AMPA receptor internalization or induction of LTD (Morishita et al., 2005; Wang et al., 2007). It is possible that these peptide inhibitors are unable to penetrate into the pool of F-actin that must be remodeled in order for AMPA 
receptor internalization to occur. Kim et al. (2003) did not find a difference in the level of LTD induced by low frequency pairedpulse stimulation in synGAP ${ }^{+/-}$hippocampal slices compared with wild type. Thus, the role of synGAP and the importance of the level of synGAP activity for long-lasting depression of EPSPs may differ depending on the induction protocol.

A second possible explanation for the disruption of longlasting depression of EPSPs is that, in addition to the critical role in cytoskeletal regulation that we have documented, the level of synGAP is also important for another step in the normal regulation of AMPA receptor internalization during removal of AMPA receptors. Data from other laboratories has already suggested that synGAP regulates AMPA receptor insertion in spines through its effect on ERK signaling (Kim et al., 2003, 2005; Krapivinsky et al., 2004; Rumbaugh et al., 2006). We propose that regulation of synGAP activity by the NMDA receptor may be a common pathway that controls spine morphology and insertion and removal of AMPA receptors in a coordinated manner to orchestrate changes in synaptic strength.

\section{References}

Arber S, Barbayannis FA, Hanser H, Schneider C, Stanyon CA, Bernard O, Caroni P (1998) Regulation of actin dynamics through phosphorylation of cofilin by LIM-kinase. Nature 393:805-809.

Bourne J, Harris KM (2007) Do thin spines learn to be mushroom spines that remember? Curr Opin Neurobiol 17:381-386.

Brewer GJ, Torricelli JR, Evege EK, Price PJ (1993) Optimized survival of hippocampal neurons in B27-supplemented Neurobasal, a new serumfree medium combination. J Neurosci Res 35:567-576.

Carlisle HJ, Kennedy MB (2005) Spine architecture and synaptic plasticity. Trends Neurosci 28:182-187.

Chen HJ, Rojas-Soto M, Oguni A, Kennedy MB (1998) A synaptic RasGTPase activating protein (p135 SynGAP) inhibited by CaM kinase II. Neuron 20:895-904.

Chen LY, Rex CS, Casale MS, Gall CM, Lynch G (2007) Changes in synaptic morphology accompany actin signaling during LTP. J Neurosci 27:5363-5372.

Delgado JY, Coba M, Anderson CN, Thompson KR, Gray EE, Heusner CL, Martin KC, Grant SG, O’Dell TJ (2007) NMDA receptor activation dephosphorylates AMPA receptor glutamate receptor 1 subunits at threonine 840. J Neurosci 27:13210-13221.

Edwards DC, Sanders LC, Bokoch GM, Gill GN (1999) Activation of LIMkinase by Pak1 couples Rac/Cdc42 GTPase signalling to actin cytoskeletal dynamics. Nat Cell Biol 1:253-259.

Ehlers MD (2000) Reinsertion or degradation of AMPA receptors determined by activity-dependent endocytic sorting. Neuron 28:511-525.

Feng G, Mellor RH, Bernstein M, Keller-Peck C, Nguyen QT, Wallace M, Nerbonne JM, Lichtman JW, Sanes JR (2000) Imaging neuronal subsets in transgenic mice expressing multiple spectral variants of GFP. Neuron 28:41-51.

Fischer M, Kaech S, Knutti D, Matus A (1998) Rapid actin-based plasticity in dendritic spines. Neuron 20:847-854.

Fleming IN, Batty IH, Prescott AR, Gray A, Kular GS, Stewart H, Downes CP (2004) Inositol phospholipids regulate the guanine-nucleotide-exchange factor Tiaml by facilitating its binding to the plasma membrane and regulating GDP/GTP exchange on Racl. Biochem J 382:857-865.

Halpain S (2000) Actin and the agile spine: how and why do dendritic spines dance? Trends Neurosci 23:141-146.

Harris KM, Stevens JK (1989) Dendritic spines of CA 1 pyramidal cells in the rat hippocampus: serial electron microscopy with reference to their biophysical characteristics. J Neurosci 9:2982-2997.

Holtmaat AJ, Trachtenberg JT, Wilbrecht L, Shepherd GM, Zhang X, Knott GW, Svoboda K (2005) Transient and persistent dendritic spines in the neocortex in vivo. Neuron 45:279-291.

Kennedy MB (1997) The postsynaptic density at glutamatergic synapses. Trends Neurosci 20:264-268.

Kennedy MB (2000) Signal-processing machines at the postsynaptic density. Science 290:750-754.

Kennedy MB, Beale HC, Carlisle HJ, Washburn LR (2005) Integration of biochemical signalling in spines. Nat Rev Neurosci 6:423-434.
Kim E, Sheng M (2004) PDZ domain proteins of synapses. Nat Rev Neurosci 5:771-781.

Kim JH, Liao D, Lau LF, Huganir RL (1998) SynGAP: a synaptic RasGAP that associates with the PSD-95/SAP90 protein family. Neuron 20:683-691.

Kim JH, Lee HK, Takamiya K, Huganir RL (2003) The role of synaptic GTPase-activating protein in neuronal development and synaptic plasticity. J Neurosci 23:1119-1124.

Kim MJ, Dunah AW, Wang YT, Sheng M (2005) Differential roles of NR2Aand NR2B-containing NMDA receptors in Ras-ERK signaling and AMPA receptor trafficking. Neuron 46:745-760.

Koh IY, Lindquist WB, Zito K, Nimchinsky EA, Svoboda K (2002) An image analysis algorithm for dendritic spines. Neural Comput 14:1283-1310.

Komiyama NH, Watabe AM, Carlisle HJ, Porter K, Charlesworth P, Monti J, Strathdee DJ, O'Carroll CM, Martin SJ, Morris RG, O'Dell TJ, Grant SG (2002) SynGAP regulates ERK/MAPK signaling, synaptic plasticity, and learning in the complex with postsynaptic density 95 and NMDA receptor. J Neurosci 22:9721-9732.

Kramár EA, Lin B, Rex CS, Gall CM, Lynch G (2006) Integrin-driven actin polymerization consolidates long-term potentiation. Proc Natl Acad Sci U S A 103:5579-5584.

Krapivinsky G, Krapivinsky L, Manasian Y, Ivanov A, Tyzio R, Pellegrino C, Ben-Ari Y, Clapham DE, Medina I (2003) The NMDA receptor is coupled to the ERK pathway by a direct interaction between NR2B and RasGRF1. Neuron 40:775-784.

Krapivinsky G, Medina I, Krapivinsky L, Gapon S, Clapham DE (2004) SynGAP-MUPP1-CaMKII synaptic complexes regulate p38 MAP kinase activity and NMDA receptor-dependent synaptic AMPA receptor potentiation. Neuron 43:563-574

Lambert JM, Lambert QT, Reuther GW, Malliri A, Siderovski DP, Sondek J, Collard JG, Der CJ (2002) Tiam1 mediates Ras activation of Rac by a PI(3)K-independent mechanism. Nat Cell Biol 4:621-625.

Lee HK, Kameyama K, Huganir RL, Bear MF (1998) NMDA induces longterm synaptic depression and dephosphorylation of the GluR1 subunit of AMPA receptors in hippocampus. Neuron 21:1151-1162.

Li S, Tian X, Hartley DM, Feig LA (2006) Distinct roles for Ras-guanine nucleotide-releasing factor 1 (Ras-GRF1) and Ras-GRF2 in the induction of long-term potentiation and long-term depression. J Neurosci 26:1721-1729.

Lüscher C, Nicoll RA, Malenka RC, Muller D (2000) Synaptic plasticity and dynamic modulation of the postsynaptic membrane. Nat Neurosci 3:545-550

Manser E, Leung T, Salihuddin H, Zhao ZS, Lim L (1994) A brain serine/ threonine protein kinase activated by $\mathrm{Cdc} 42$ and Racl. Nature 367:40-46.

Markham JA, Fifková E (1986) Actin filament organization within dendrites and dendritic spines during development. Brain Res 392:263-269.

Matsuzaki M, Honkura N, Ellis-Davies GC, Kasai H (2004) Structural basis of long-term potentiation in single dendritic spines. Nature 429:761-766.

Matus A (2000) Actin-based plasticity in dendritic spines. Science 290:754-758.

Morishita W, Marie H, Malenka RC (2005) Distinct triggering and expression mechanisms underlie LTD of AMPA and NMDA synaptic responses. Nat Neurosci 8:1043-1050.

Niwa R, Nagata-Ohashi K, Takeichi M, Mizuno K, Uemura T (2002) Control of actin reorganization by Slingshot, a family of phosphatases that dephosphorylate ADF/cofilin. Cell 108:233-246.

Norris CM, Korol DL, Foster TC (1996) Increased susceptibility to induction of long-term depression and long-term potentiation reversal during aging. J Neurosci 16:5382-5392.

Nusser Z, Lujan R, Laube G, Roberts JD, Molnar E, Somogyi P (1998) Cell type and pathway dependence of synaptic AMPA receptor number and variability in the hippocampus. Neuron 21:545-559.

Oh JS, Manzerra P, Kennedy MB (2004) Regulation of the neuron-specific Ras GTPase-activating protein, synGAP, by $\mathrm{Ca} 2+/$ calmodulindependent protein kinase II. J Biol Chem 279:17980-17988.

Okamoto K, Nagai T, Miyawaki A, Hayashi Y (2004) Rapid and persistent modulation of actin dynamics regulates postsynaptic reorganization underlying bidirectional plasticity. Nat Neurosci 7:1104-1112.

Pak DT, Yang S, Rudolph-Correia S, Kim E, Sheng M (2001) Regulation of dendritic spine morphology by SPAR, a PSD-95-associated RapGAP. Neuron 31:289-303.

Patton BL, Molloy SS, Kennedy MB (1993) Autophosphorylation of type II 
CaM kinase in hippocampal neurons: localization of phospho-and dephosphokinase with complementary phosphorylation site-specific antibodies. Mol Biol Cell 4:159-172.

Penzes P, Johnson RC, Alam MR, Kambampati V, Mains RE, Eipper BA (2000) An isoform of kalirin, a brain-specific GDP/GTP exchange factor, is enriched in the postsynaptic density fraction. J Biol Chem 275:6395-6403.

Peters A, Kaiserman-Abramof IR (1970) The small pyramidal neuron of the rat cerebral cortex. The perikaryon, dendrites and spines. Am J Anat 127:321-355.

Quinlan EM, Halpain S (1996) Postsynaptic mechanisms for bidirectional control of MAP2 phosphorylation by glutamate receptors. Neuron $16: 357-368$

Rumbaugh G, Adams JP, Kim JH, Huganir RL (2006) SynGAP regulates synaptic strength and mitogen-activated protein kinases in cultured neurons. Proc Natl Acad Sci U S A 103:4344-4351.

Soosairajah J, Maiti S, Wiggan O, Sarmiere P, Moussi N, Sarcevic B, Sampath R, Bamburg JR, Bernard O (2005) Interplay between components of a novel LIM kinase-slingshot phosphatase complex regulates cofilin. EMBO J 24:473-486.

Tolias KF, Bikoff JB, Burette A, Paradis S, Harrar D, Tavazoie S, Weinberg RJ, Greenberg ME (2005) The Rac1-GEF Tiam1 couples the NMDA recep- tor to the activity-dependent development of dendritic arbors and spines. Neuron 45:525-538.

Vazquez LE, Chen HJ, Sokolova I, Knuesel I, Kennedy MB (2004) SynGAP regulates spine formation. J Neurosci 24:8862-8872.

Wang XB, Yang Y, Zhou Q (2007) Independent expression of synaptic and morphological plasticity associated with long-term depression. J Neurosci 27:12419-12429.

Wang Y, Shibasaki F, Mizuno K (2005) Calcium signal-induced cofilin dephosphorylation is mediated by Slingshot via calcineurin. J Biol Chem 280:12683-12689.

Xie Z, Srivastava DP, Photowala H, Kai L, Cahill ME, Woolfrey KM, Shum CY, Surmeier DJ, Penzes P (2007) Kalirin-7 controls activity-dependent structural and functional plasticity of dendritic spines. Neuron 56:640-656.

Yang N, Higuchi O, Ohashi K, Nagata K, Wada A, Kangawa K, Nishida E, Mizuno K (1998) Cofilin phosphorylation by LIM-kinase 1 and its role in Rac-mediated actin reorganization. Nature 393:809-812.

Zhou Q, Xiao M, Nicoll RA (2001) Contribution of cytoskeleton to the internalization of AMPA receptors. Proc Natl Acad Sci U S A 98:1261-1266.

Zuo Y, Lin A, Chang P, Gan WB (2005) Development of long-term dendritic spine stability in diverse regions of cerebral cortex. Neuron 46:181-189. 